CIRJE-F-1140

\title{
Collective Reputation and Learning in Political Agency Problems
}

\author{
Satoshi Kasamatsu \\ The University of Tokyo \\ Daiki Kishishita \\ Graduate School of Economics, The University of Tokyo
}

January 2020

CIRJE Discussion Papers can be downloaded without charge from:

http://www.cirje.e.u-tokyo.ac.jp/research/03research02dp.html

Discussion Papers are a series of manuscripts in their draft form. They are not intended for circulation or distribution except as indicated by the author. For that reason Discussion Papers may not be reproduced or distributed without the written consent of the author. 


\title{
Collective Reputation and Learning in Political Agency Problems*
}

\author{
Satoshi Kasamatsu ${ }^{\dagger}$ and Daiki Kishishita ${ }^{\ddagger}$
}

January 25, 2020

This study aims to reveal how an endogenous change in political trust affects the performance of a representative democracy. To this end, we construct a twoperiod political agency model wherein voters face uncertainty about the distribution of politicians' types (model uncertainty) as well as each individual politician's type. Such model uncertainty allows political trust to endogenously change over time, whereas political trust is invariant without model uncertainty. We show that model uncertainty substantially increases corruption. Furthermore, it generates self-fulfilling multiple equilibria: a high-accountability equilibrium and a lowaccountability equilibrium coexist. In countries experiencing democracy only for a short time, model uncertainty would be severe. Our results indicate that democratic performance tends to be low and even similar countries could experience different performances depending on citizens' expectations in such new democracies. By extending the model, we also discuss the relationship between political trust and the rise of an outsider candidate.

Keywords: Political trust; Model uncertainty; Corruption; Multiple equilibria; Political agency

JEL classification: D72; D73; D83

*We are grateful to Keisuke Hattori, Akitaka Kamijo, Akihiko Matsui, Nobuhiro Mizuno, Susumu Sato; the participants of the 2019 Annual Meeting of the Japan Public Choice Society at Kansai University; and the seminar participants at Osaka University of Economics and Yokohama National University for their helpful comments. Kasamatsu was financially supported by JSPS Grant-in-Aid for Research Activity Start-up (19K23188). Kishishita was financially supported by JSPS Grant-in-Aid for JSPS Research Fellows (17J02113). All remaining errors are our own.

${ }^{\dagger}$ Faculty of Economics, The University of Tokyo. 7-3-1, Hongo, Bunkyo-ku, Tokyo, Japan. 113-0033. E-mail: kasamatsu00@gmail.com

¥Graduate School of Economics, The University of Tokyo. 7-3-1, Hongo, Bunkyo-ku, Tokyo, Japan. 113-0033. E-mail: daiki.kishishita@gmail.com 


\section{Introduction}

Political trust has been regarded as a major determinant of the performance of a representative democracy 1 For example, in the famous report on the crisis of democracy, Crozier, Huntington and Watanuki (1975) argue that political distrust could have destructive effects on the functioning of a representative democracy. In addition, in recent years, it has been empirically found that political distrust decreases the support for mainstream parties and induces the rise of populist parties (Guiso et al., 2017).

To understand these issues, it is absolutely necessary to consider an endogenous change in political trust. First, political trust changes over time (Van der Meer, 2017). Second, it is not exogenous. Politicians' behaviors change the political trust level, which in turn changes voting behaviors, thereby affecting politicians' actions. The purpose of the present study is to uncover the effect of an endogenous change in political trust on the performance of a representative democracy. To be specific, we focus on the trust of politicians' quality on average, though political trust also has various other aspects.

Despite its relevance, existing studies have not explored this issue because standard models do not allow political trust to endogenously change over time. Suppose that the fraction of honest politicians (i.e., high-quality politicians) is $\alpha$. This $\alpha$ is the collective reputation that politicians as a whole have and can be regarded as political trust. In standard political agency models such as Besley (2006), it is assumed that voters do not know each politician's type, but they know the value of $\alpha$ (i.e., the probability distribution of politicians' types) (see Duggan and Martinelli (2017) for a literature review). Consequently, while each politician's individual reputation (i.e., the probability of the politician being honest) endogenously changes, the collective reputation $\alpha$ is invariant. Because of this setting, existing studies have ignored the endogenous change in political trust.

However, the assumption that voters know the value of $\alpha$ is not necessarily reasonable. Voters have only limited learning opportunities so they face a severely constrained information environment. Hence, even the probability distribution (i.e., the value of $\alpha$ ) might be uncertain, which is called model uncertainty. ${ }^{2}$ In such an environment, voters update their belief about $\alpha$ based on politicians' actions, and thus political trust endogenously changes over time. By comparing the cases with and without model uncertainty, we uncover the effect of an endogenous change in political trust.

For this purpose, we construct a two-period election model with a representative voter à la

\footnotetext{
${ }^{1}$ See Van der Meer (2017) for a literature review of the empirical analysis of political trust in political sciences.

${ }^{2}$ In the political economy literature, Chen and Suen (2016) and Chen and Suen (2017) use this terminology to describe the situation in which players do not know the probability distribution. It is also called Knightian uncertainty or ambiguity in the decision theory (Gilboa and Schmeidler. 1989). Here, we use neither Knightian uncertainty nor ambiguity because we do not assume any ambiguity aversion, which is the central issue of the decision theory under uncertainty. For a literature review on the effect of ambiguity aversion in political economy, see Bade (2013).
} 
Besley (2006). In period 1, the incumbent politician chooses a policy among two alternatives: policy 0 is the non-corrupt policy, while policy 1 is the corrupt policy. The voter then decides whether to reelect the incumbent politician or elect a challenger. In period 2, the elected politician chooses a policy. Politicians are divided into three types: the ethical type whose preferences are aligned with that of the voter, the opportunistic type who prefers policy 1 but can be controlled, and the non-ethical type who always chooses policy 1 . The voter does not know each politician's type. On top of this, the fraction of the ethical type, denoted by $\alpha$, is also uncertain for the voter in the presence of model uncertainty ${ }^{3}$

We characterize equilibria in the cases with and without model uncertainty. We then show the two results: model uncertainty (i) makes it more difficult for the voter to control the opportunistic type politician in period 1, and (ii) creates self-fulfilling multiple equilibria in period 1 .

We first show that model uncertainty increases corruption through an endogenous change in political trust. Corruption lowers the probability of reelection, while non-corruption increases the probability of reelection. The difference between these two reelection probabilities creates the opportunistic type's incentive not to be corrupt in period 1. However, under model uncertainty, changes in the reelection probabilities become moderate in both corruption and non-corruption cases. As a result, the opportunistic type has less incentive not to be corrupt, leading to low accountability.

To understand the mechanism, suppose first that the voter observes corruption. Then, the incumbent politician's reputation is severely undermined, inducing low reelection probability. However, in the presence of model uncertainty, this is not the complete picture because collective reputation also changes. Corruption signals that the fraction of the ethical type politicians is small, and thus the voter updates their belief about $\alpha$ and believes that $\alpha$ is likely to be low. That is, political distrust increases. Hence, the voter becomes concerned that the challenger is also not the ethical type. Furthermore, such political distrust increases the opportunistic type's equilibrium corruption level. From these two negative effects, political distrust makes the challenger less attractive to the voter. Consequently, even after corruption, the reelection probability of the incumbent does not decrease so much in the presence of model uncertainty. In the case of non-corruption, the opposite occurs. The incumbent's reputation is improved, inducing the high reelection probability. However, in the presence of model uncertainty, noncorruption increases political trust, which in turn increases the value of the challenger. As a result, the incumbent's reelection probability does not increase so much. As such, punishment for corruption and reward for non-corruption become weakened, resulting in low accountability.

Next, we show that a high-accountability equilibrium and a low-accountability equilibrium could coexist under model uncertainty. As the opportunistic type politician is more likely to choose the non-corrupt policy, the non-corrupt policy becomes a less informative signal of the incumbent being the ethical type. Hence, the opportunistic type has less incentive not to be

\footnotetext{
${ }^{3}$ To be precise, we assume that the fraction of the non-ethical type is certain because this behavioral type is introduced to eliminate implausible off-path belief formations and thus this type is not our main focus.
} 
corrupt as the fraction of the opportunistic type choosing corruption decreases (i.e., the game exhibits strategic substitution). Without model uncertainty, this creates a unique equilibrium (Besley, 2006).

Model uncertainty changes the situation. When period 1's policy is uninformative about the incumbent's type, it is also uninformative about $\alpha$. Hence, the political trust level becomes less sensitive to policymaking in period 1 , meaning that the negative effect of model uncertainty on the punishment and reward mechanism is mitigated. That is, under model uncertainty, as the opportunistic type politician is more likely to choose non-corruption, the reward and punishment mechanism works better. When this effect is sufficiently large, the game exhibits (locally) strategic complementarity, which creates multiple equilibria. On the one hand, when the voter believes that most of the opportunistic types are corrupt, the reward and punishment mechanism does not work, and thus corruption is realized. On the other hand, when the voter believes that most of the opportunistic types are not corrupt, the reward and punishment mechanism works well, and thus the clean environment is realized.

These two results (low accountability and multiplicity of equilibria) show that model uncertainty (i.e., an endogenous change in political trust) drastically changes the nature of political agency problems. In particular, the second result indicates that the existing results relying on the strategic substitution property might crucially hinge on the implicit assumption that there is no model uncertainty. $4^{4}$

Furthermore, the presented results provide sharp explanations for the two observations about corruption. The first observation is about corruption in new democracies. Several empirical studies find that a short exposure to democracy predicts a high level of corruption (e.g., Treisman, 2000; Rock, 2009). That is, corruption tends to be prevailing in new democracies. One distinction between new democracies and established democracies would be the extent of model uncertainty. Compared to established democracies, voters in new democracies would face severe model uncertainty and the political trust level is not well established because of limited experience. The low accountability result indicates that new democracies could experience high corruption levels simply because voters face model uncertainty and the political trust level is not established. This finding is important from the perspective of democratic consolidation since corruption undermines the trust for democracy. It is often the case that countries that have experienced democratization revert to dictatorship after only a brief democratic period (Svolik, 2008). Our result indicates that model uncertainty is one source of such a break-up of democracy.

The second empirical observation is the variation of the level of corruption even among similar regions. In reality, even within the same country wherein regions seem to have similar institutions, there are significant differences in corruption such as across American states (e.g., Glaeser and Saks, 2006). Although some of the differences can be explained by the differences

\footnotetext{
${ }^{4}$ The canonical model of electoral accountability à la Besley (2006) has been widely applied such as in the analysis of intergovernmental competition (e.g., Besley and Case, 1995, Besley and Smart. 2007).
} 
in fundamentals. $5^{5}$ our result on the multiplicity of equilibria indicates that institutional variation is unnecessary for generating variation in corruption.

In addition, our theory provides explanations for a variety of empirical findings: that corruption increases political distrust (Seligson, 2002); the punishment for corrupt politicians is weak (Chong et al., 2014; Boas, Hidalgo and Melo, 2019); the support for a challenger decreases after the incumbent's corruption (Chong et al., 2014); an audit on corruption reduces corruption but not because of the electoral mechanism (Avis, Ferraz and Finan, 2018); and the electoral cost of corruption depends on how widespread corruption is (Klašnja and Tucker, 2013). For each finding, another explanation is possible, and thus it is not the case that only our results can explain them. Rather, the novelty of our study is to reveal that various findings can be explained in a unified manner by solely introducing model uncertainty and the associated endogenous change in political trust.

So far, we have assumed that all candidates suffer from political trust. However, this might not be the case for outsider candidates. In the empirical literature, it is known that political distrust induces support for populist parties and outsider candidates (Guiso et al., 2017). At the end of the study, we extend the model to introduce an outsider candidate who does not suffer from collective reputation, but instead has low ability because of a lack of experience 6

Though we have framed our model in the context of the political economy, it is applicable to various agency problems. For instance, suppose that a consumer decides whether to continue to buy the product s/he has used or replace it with a new brand. Each firm decides the quality level, which is uncertain for the consumer. Each firm's type is about productivity. Our results indicate that when the productivity distribution is uncertain, the equilibrium quality level decreases and multiple equilibria exist.

The remaining paper is organized as follows. Section 2 discusses related literature. Section 3 presents our model and Sections 4 and 5 analyze it. Section 6 discusses outsider candidates. Section 7 outlines our conclusions.

\section{Related Literature}

- Political economy in the presence of model uncertainty: Voters typically face a severely constrained information environment. However, there are only a few studies that analyze learning about the distribution under model uncertainty. ${ }^{7}$ Meirowitz and Tucker (2013) analyze citizens' costly actions on protests. By introducing model uncertainty about governments' qualities, they demonstrate that even if a protest occurs once, protests might not occur again in the future despite

\footnotetext{
${ }^{5}$ Indeed, Glaeser and Saks (2006) show that some explanations are consistent with the data.

Buisseret and Van Weelden (forthcoming) analyze the rise of outsider candidates by using a citizen candidate model that incorporates primary elections.

${ }^{7}$ Beyond the political economy literature, learning about the distribution has been explored in the context of search theory (e.g., Burdett and Vishwanath, 1988). However, this literature does not take agency problems into account.
} 
an intervening period of bad governance because citizens come to think that any government is bad and thus a regime change is meaningless ${ }^{8}$ Chen and Suen (2017) also analyze protests and show that learning about the distribution of governments' qualities explains the phenomenon called middle-class activism.9 However, their models are purely adverse selection models in that governments do not take any actions. ${ }^{10}$ Our contribution is to uncover how model uncertainty affects politicians' actions through interaction with an endogenous change in political trust ${ }^{11}$

From a broader perspective, our study contributes to the literature of political agency problems by showing a way that a challenger's reputation is endogenously determined. In the canonical model, the challenger's reputation is assumed to be invariant until an election. To relax this strong assumption, Dewan and Hortala-Vallve (2019) allow the challenger to campaign in their own type. Our study illustrates that an endogenous change in political trust is another source of the endogenous change in the challenger's reputation.

- Multiplicity of equilibria and corruption: In the real world, both high-corrupt countries and low-corrupt countries coexist. To explain this, the strategic complementarity and the associated multiplicity of equilibria have been extensively discussed (e.g., Andvig and Moene, 1990; Mauro, 2004; Mishra, 2006). For instance, Mishra (2006) shows that as others become corrupt, the cost of compliance increases, which induces multiple equilibria. One shortcoming of this literature is that most of them focus on the interaction between agents (bureaucrats or politicians), not between voters and the agents. Since the control by voters might enable society to escape from a high-corruption equilibrium, it is important to analyze whether the multiplicity of equilibria remains in electoral accountability models. Indeed, in the canonical accountability model à la Besley (2006), the game exhibits strategic substitution so that the equilibrium is unique. In contrast, we succeed in showing the multiplicity of equilibria by introducing model uncertainty and the associated endogenous formation in political trust.

The exception showing the multiplicity of equilibria in the model consisting of both voters and politicians is Klašnja, Little and Tucker (2018). Their mechanism is fairly different from ours - there is neither model uncertainty nor an endogenous change in political trust over time. Instead, the key for their results is the endogenous entry of politicians. ${ }^{12}$ Our contribution is

Svolik (2013) analyzes a repeated elections model with two candidates and show that voters end up stopping costly monitoring after repeated bad governance due to a similar mechanism, though there is no model uncertainty in his model.

9 Chen and Suen (2016) also analyze learning in the presence of model uncertainty in the context of protests, though the uncertainty is not about governments' types.

${ }^{10}$ In addition, Banks and Sundaram (1990) analyze model uncertainty in repeated elections, but their model is also a purely adverse selection one.

${ }^{11}$ In the general context of reputation building, Tirole (1996) and Levin (2009) analyze collective reputation by considering a different setting with no model uncertainty. Their models do not have the two key properties of our model- a single individual agent's action does not affect collective reputation, and there is no competition between agents such as the electoral competition between the incumbent and the challenger in their models.

${ }^{12}$ In the analysis of politicians' effort choices, Ashworth, Bueno de Mesquita and Friedenberg (2017) show multiple equilibria in the model à la Holmström (1999) wherein both politicians and voters do not know the politicians' 
to show that society cannot escape from the multiplicity of equilibria even in the presence of elections by emphasizing the role of model uncertainty.

\section{The Model}

Following Besley (2006), we construct a two-period election model with a representative voter (hereafter, the voter). At the beginning of period 1, there is an incumbent politician. After policy implementation, the voter decides whether to reelect the incumbent or elect a challenger. In period 2, the elected politician implements policy and the game ends. The discount factor is $\delta \in(0,1]$.

\subsection{Politicians}

In period $t$, the policymaker chooses policy $x_{t} \in\{0,1\}$, where $x_{t}=0$ is the voter-optimal policy and $x_{t}=1$ is the corrupt policy.

Politicians are divided into three types: ethical type, opportunistic type, and non-ethical type. The ethical type is the politician whose ideal policy is policy 0 ; this type is assumed to always choose the voter-optimal policy $x_{t}=0$

On the contrary, the opportunistic type is biased; the ideal policy is policy 1. In particular, the payoff is given by

$$
\mathbf{1}_{1}\left(-\left|x_{1}-1\right|+b\right)+\delta \mathbf{1}_{2}\left(-\left|x_{2}-1\right|+b+r \pi\left(x_{1}, x_{2}\right)\right)
$$

where $\mathbf{1}_{t}$ is the indicator function which takes one if and only if the politician is in office in period $t .-\left|x_{t}-1\right|$ is the loss due to policy mismatch, while $b>0$ represents the office-seeking motivation 14 Although this type of politician's ideal policy is policy $1, \mathrm{~s} /$ he does not necessarily choose this policy because s/he cares about reelection. If corruption (i.e., the implementation of policy 1) prevents reelection, the opportunistic type might implement the voter-optimal policy in period 1. The office-seeking motivation serves as the role of creating this possibility of controlling the opportunistic type of politician. Here, period 2's payoff contains an additional term: $r \pi\left(x_{1}, x_{2}\right)$, where $r \geq 0$. In our model, the game ends in period 2 so that there is no reelection possibility after period 2 . However, even in such a situation, politicians might care about their own reputation because a low reputation might damage the quality of the post-political life or their own soft legacy (Fong, Malhotra and Margalit, 2019). To take such considerations into account, we introduce this term. Here, $\pi\left(x_{1}, x_{2}\right)$ is the updated belief that the voter holds at

ability. In contrast, we consider the model with information asymmetry. Moreover, there is no model uncertainty in their model.

${ }^{13}$ By introducing a reasonable belief restriction, we can show that the ethical type indeed always chooses policy 0 at the equilibrium even if s/he has a payoff function like the opportunistic type and behaves strategically.

${ }^{14}$ This setting implies that the payoff when not in the office is normalized to be zero. 
the end of period 2 about the probability of the policymaker in period 2 being the ethical type given $\left(x_{1}, x_{2}\right){ }^{15}$

In addition to these two types, we introduce a behavioral type: non-ethical type. This type of politicians is assumed to always choose policy 1 independently of voters' actions. The existence of such a behavioral type enables us to avoid unnecessary considerations about off-path belief formations, and thus various studies on reputation have introduced this type of agent.

In summary, we have three types of politicians: the ethical type, the opportunistic type, and the non-ethical type. The non-ethical type - who is the behavioral type - exists with probability $1-q$, where $q \in(0,1)$. That is, the sum of the fractions of the ethical type and the opportunistic type is $q$. Among $q$ fraction of politicians, $\alpha$ fraction of them is the ethical type. Hence, $\alpha q$ fraction of politicians is the ethical type, whereas $(1-\alpha) q$ fraction is the opportunistic type. Each politician's type is independently drawn from this distribution.

\subsection{Voter}

The voter does not know each politician's type, whereas each politician knows their own type. The voter's payoff from policy $x_{t}$ in period $t$ is $-\left|x_{t}\right|$ because the voter-optimal policy is policy 0 .

After observing the policy implemented in period 1, at the beginning of period 2, the voter faces an election. Let $V(I)$ be the voter's expected payoff from policy in period 2 when reelecting the incumbent given $x_{1}: V(I) \equiv E\left[-\left|x_{2}\right| \mid x_{1}\right.$, Incumbent $]$. Similarly, let $V(C)$ be the expected payoff when electing a challenger: $V(C) \equiv E\left[-\left|x_{2}\right| \mid x_{1}\right.$, Challenger $]$. We suppose probabilistic voting. That is, the voter votes for the incumbent politician if and only if

$$
V(I)+\varepsilon \geq V(C)
$$

where $\varepsilon$ follows a uniform distribution $U\left[-\frac{1}{2 \psi}, \frac{1}{2 \psi}\right]$. Here, $\varepsilon$ is the valence advantage of the incumbent politician, which is realized at the timing of the election. For instance, when the economy is growing, the voter might highly evaluate the incumbent's ability so that the incumbent's valence advantage would become high. However, whether the economy will be growing is stochastic at the timing of policy implementation. The current setting captures such a stochastic term. Note that $\psi$ is assumed to be sufficiently small in order to guarantee that the voter always votes probabilistically:

Assumption 1. The following inequality holds:

$$
\psi<\frac{1}{2 \max \{q, 1-\underline{\alpha} q\}}
$$

\footnotetext{
$1 5 \longdiv { \text { Kartik and Van Weelden } } ( 2 0 1 9 a )$ also introduce a similar reputation concern for the last period.
} 


\subsection{Model Uncertainty}

In our model, the good type politician is the ethical type, and thus when the voter believes that most of the politicians are the ethical type (i.e., when $\alpha q$ is high), it can be assumed that political trust is high.

In order to create the endogenous change in political trust, we suppose that players do not know the value of $\alpha$ i.e., they face model uncertainty. ${ }^{16}$ Note that the value of $q$ is known just for simplicity. To be specific, $\alpha \in\{\bar{\alpha}, \underline{\alpha}\}$ and which value $\alpha$ takes is uncertain. Here, $0<\underline{\alpha}<\bar{\alpha}<1$. At the beginning of the game, nature chooses the value of $\alpha$ to be $\bar{\alpha}$ with probability $\phi$. The voter updates the belief about the value of $\alpha$ following the Bayes rule.

As a benchmark case, we also analyze the case wherein there is no model uncertainty. To be consistent with the model uncertainty case, we assume that $\alpha=\alpha^{e} \equiv \phi \bar{\alpha}+(1-\phi) \underline{\alpha}$. Hence, in the case without model uncertainty, players know that $\alpha$ is deterministically equal to the expected value of $\alpha$ in the presence of model uncertainty.

By comparing these two cases, we analyze the effect of model uncertainty.

\subsection{Timing of the Game and Equilibrium Concept}

The timing of the game is given as follows:

Period 1

1. Nature chooses the value of $\alpha$.

2. The incumbent chooses $x_{1}$.

3. The voter observes $x_{1}$ and $\varepsilon$ is realized.

Period 2

1. The voter decides whether to reelect the incumbent.

2. The chosen policymaker chooses $x_{2}$.

3. The voter observes $x_{2}$ and $\pi$ is formed.

4. The payoffs are realized.

The equilibrium concept is the perfect Bayesian equilibrium. We allow players to take mixed strategies. To eliminate implausible off-path belief formation, we also impose the following belief restriction: if the off-path policy is observed, the voter believes that the policymaker who implemented the policy is the opportunistic type. In our model, the ethical type always chooses policy 0 and the non-ethical type always chooses policy 1 . Hence, the off-path policy can be

\footnotetext{
${ }^{16}$ The assumption that politicians do not know $\alpha$ is not crucial since the value of $\alpha$ is payoff-irrelevant for politicians. So long as we focus on equilibria in which players' equilibrium strategies only depend on the payoff-relevant information, the same results hold if politicians know the value of $\alpha$.
} 
chosen only by the opportunistic type. Given this nature of our game, the presented belief restriction is reasonable. Throughout the analysis, we focus on the perfect Bayesian equilibrium satisfying this belief restriction.

\section{Equilibrium in Period 2}

We solve the game backwardly. Since the ethical type always chooses policy 0 and the nonethical type always chooses policy 1 , we focus on the opportunistic type's equilibrium strategy. We denote the opportunistic type's equilibrium probability of choosing policy 0 by $\sigma_{2}^{*}$. In addition, let $\tilde{q}_{e}$ be the probability of the policymaker in period 2 being the ethical type; let $\tilde{q}_{o}$ be the probability of the policymaker in period 2 being the opportunistic type; and let $\tilde{q}_{n}$ be the probability of the policymaker in period 2 being the non-ethical type. These are the voter's beliefs just after the election so they depend on whether the policymaker in period 2 is the incumbent in period 1 and what policy was implemented in period 1.

Based on these notations, We obtain the following simple characterization of $\sigma_{2}^{*}$. The appendix contains the omitted proofs.

Lemma 1. The equilibrium strategy of the opportunistic type in period 2 is given as follows:

(i) When $\tilde{q}_{e}>0$,

$$
\sigma_{2}^{*}\left(\tilde{q}_{e}, \tilde{q}_{o}\right)=\left\{\begin{array}{l}
0 \text { if } r \leq 1 \\
\frac{(r-1) \tilde{q}_{e}}{\tilde{q}_{o}} \text { if } 1<r<\frac{\tilde{q}_{o}}{\tilde{q}_{e}}+1 \\
1 \text { if } r \geq \frac{\tilde{q}_{o}}{\tilde{q}_{e}}+1
\end{array} .\right.
$$

(ii) When $\tilde{q}_{e}=0, \sigma_{2}^{*}\left(\tilde{q}_{e}, \tilde{q}_{o}\right)=0$.

In our model, period 2 is the end of the world, and thus the policymaker in period 2 has no reelection concern. However, for sufficiently large $r$, the voter can prevent the opportunistic type from corruption. This is because the politician has reputation concerns in period 2 when $r$ is sufficiently large.

The important property in the above lemma is regarding the case wherein the opportunistic type chooses a mixed strategy. Here, higher $\tilde{q}_{e} / \tilde{q}_{o}$ induces a high probability of the opportunistic type choosing the voter-optimal policy. That is, as political trust decreases, it becomes more difficult to control the opportunistic politician. When the fraction of the ethical type is limited, the voter thinks that the politician choosing policy 0 is likely to be the bad type (i.e., the opportunistic type). Hence, in that case, the opportunistic type cannot obtain a high reputation by choosing the voter-optimal policy, which results in low accountability in period 2.

In order to avoid unnecessary complication, we impose one assumption that guarantees that $\sigma_{2}^{*}<1$ holds for the challenger:

Assumption 2. $r$ is sufficiently small so that $r<1 / \bar{\alpha}$. 


\subsection{Equilibrium after Corruption}

\subsubsection{Equilibrium Strategy}

Depending on whether the voter observed corruption in period 1 or not, the equilibrium action changes. Let $\sigma_{2}^{*}\left(x_{1} \mid I\right)$ be $\sigma_{2}^{*}$ given $x_{1}$ when the incumbent politician in period 1 is reelected. Similarly, let $\sigma_{2}^{*}\left(x_{1} \mid C\right)$ be that when the challenger is elected. In this subsection, we analyze the case in which the voter observed corruption in period 1 (i.e., $x_{1}=1$ ).

For this purpose, first, suppose that the incumbent politician is reelected in spite of her/his corruption in period 1 . Since the ethical type never chooses policy $1, \tilde{q}_{e}=0$ i.e., the incumbent politician is already known to be bad after corruption. Hence, the incumbent politician has no incentive to choose the voter-optimal policy in period 2 as seen in Lemma 1(ii).

Next, suppose that the challenger is elected. When there is no model uncertainty, corruption in period 1 has no information about the challenger's type. Hence, $\tilde{q}_{e}=\alpha q$ and $\tilde{q}_{o}=(1-\alpha) q$.

On the contrary, in the presence of model uncertainty, the situation drastically changes. In this case, the voter does not know the value of $\alpha$ so the voter updates their belief about $\alpha$ based on corruption in period 1 . Given the opportunistic type's equilibrium strategy in period 1 , which is denoted by $\sigma_{1}^{*}, \phi$ is updated to $\phi(1)$ :

$$
\phi(1)=\frac{\phi\left[\left(1-\sigma_{1}^{*}\right)(1-\bar{\alpha}) q+1-q\right]}{\phi\left[\left(1-\sigma_{1}^{*}\right)(1-\bar{\alpha}) q+1-q\right]+(1-\phi)\left[\left(1-\sigma_{1}^{*}\right)(1-\underline{\alpha}) q+1-q\right]} \leq \phi,
$$

where the strict inequality holds if $\sigma_{1}^{*} \neq 1$. Since corruption indicates that the fraction of the ethical type is only small, $\phi$ is downwardly updated. Consequently,

$$
\tilde{q}_{e}=(\phi(1) \bar{\alpha}+(1-\phi(1)) \underline{\alpha}) q<\alpha^{e} q ; \quad \tilde{q}_{o}=[1-(\phi(1) \bar{\alpha}+(1-\phi(1)) \underline{\alpha})] q>\left(1-\alpha^{e}\right) q
$$

when $\sigma_{1}^{*} \neq 1$. Since the change in $\tilde{q}_{e} / \tilde{q}_{o}$ induces the change in the opportunistic type's behavior, the challenger's equilibrium behavior becomes different depending on the presence of model uncertainty.

Based on these observations, we obtain the following result.

Proposition 1. (i) $\sigma_{2}^{* N}(1 \mid I)=\sigma_{2}^{* M}(1 \mid I)=0$.

(ii) $\sigma_{2}^{* N}(1 \mid C) \geq \sigma_{2}^{* M}(1 \mid C)$, where equality holds if and only if $r \leq 1$.

Here, the subscript $N$ represents the case without model uncertainty, whereas $M$ represents the case with model uncertainty.

Irrespective of the existence of model uncertainty, the equilibrium strategy becomes the same when the incumbent is reelected. This is because model uncertainty has nothing to do with updating the incumbent's type.

On the contrary, the effect on the challenger is different. In the presence of model uncertainty, corruption induces the updating of the distribution of the challenger's type. As a result, $\tilde{q}_{e} / \tilde{q}_{o}$ 
decreases even for the challenger. That is, corruption magnifies political distrust, which is consistent with the empirical literature (Seligson, 2002). Since political distrust decreases the performance of the policymaker (Lemma 11), corruption decreases even the challenger's performance in the presence of model uncertainty. This is (ii) in the above proposition.

\subsubsection{Election}

This change in the challenger's performance also affects the electoral outcome at the beginning of period 2. Let $P^{*}\left(x_{1}\right)$ be the reelection probability of the incumbent given $x_{1}$. We obtain the following proposition.

Proposition 2. $P^{* N}(1) \leq P^{* M}(1)<0.5$, where equality holds for the first one only when $\sigma_{1}^{* M}=1$

The corrupt incumbent politician is evidently the bad type of politician, who will also become corrupt in the next period. Hence, such a politician should not be reelected. Without model uncertainty, this selection works well because corruption makes the incumbent less attractive in the sense that $V(I)$ (the voter's expected payoff when reelecting the incumbent) decreases. However, in the presence of model uncertainty, corruption magnifies political distrust so that even the challenger becomes less attractive (i.e., $V(C)$ decreases). Hence, the reelection probability does not substantially decrease even if the voter observes the incumbent's corruption ${ }^{17}[8$

Propositions 1 and 2 together indicate that corruption substantially decreases electoral accountability in period 2 when the voter faces model uncertainty. For electoral accountability, there are two important factors: the discipline effect (the effect of disciplining the bad type) and the selection effect (the effect on selecting the good type) (Besley, 2006). In the presence of model uncertainty, the corruption information in period 1 weakens the discipline effect for the challenger as well as the incumbent. What makes things worse is that because of this result, the selection effect also becomes weak. Due to these two negative effects, electoral accountability in period 2 becomes low.

This mechanism induced by model uncertainty is consistent with empirical evidence. The standard theory predicts that the reelection probability of the incumbent will substantially decrease after voters receive information about the incumbent's corrupt behaviors. However, several empirical studies show that the electoral punishment for corruption is not so strong (Chong et al., 2014; Boas, Hidalgo and Melo, 2019). In particular, Chong et al. (2014) show that one of the reasons is that the vote share of the challenger also decreases after voters receive the incumbent's corruption information, which suggests that the distrust toward the challenger

\footnotetext{
$1 \sqrt{\text { Agerberg }}$ (2019) empirically finds that voters do not punish the corrupt incumbent when there is no clean alternative. Our mechanism is consistent with such a finding.

${ }^{18}$ When $\psi$ goes to infinity (i.e., the voting is deterministic), $P^{* N}(1)=P^{* M}(1)$ always holds because $V(I)>V(C)$ is satisfied even in the presence of model uncertainty. Hence, our result crucially depends on the assumption of probabilistic voting. Indeed, in various political agency problems, probabilistic voting and deterministic voting yield different results (Kartik and Van Weelden, 2019b).
} 
is also magnified by the incumbent's corruption. These are consistent with our prediction. Furthermore, by estimating a structural model, Avis, Ferraz and Finan (2018) show that an audit on corruption reduces corruption in Brazilian municipalities, but the main mechanism is not the electoral one but the legal sanction. Although empirically identifying the mechanism is difficult, our result provides one rationale for this empirical fact. In the presence of model uncertainty, corruption makes it difficult to discipline challengers as well as the incumbent politician, and thus publicly detecting corruption does not necessarily reduce corruption.

\subsubsection{How to Escape from This Curse}

As we have seen, both the discipline and selection effects are undermined after corruption in the presence of model uncertainty. How severe this curse is, crucially depends on the equilibrium in period 1 . For this, we have the following result.

Proposition 3. $P^{* M}(1)$ is decreasing in $\sigma_{1}^{* M}$.

This proposition indicates that the more disciplined the incumbent in period 1 is, the easier it is to punish the corrupt politician in the next election. The mechanism comes from the fact that the information value of the incumbent's action for the distribution of politicians' types is dependent upon $\sigma_{1}^{* M}$. When almost all the opportunistic type politicians choose policy 0 (i.e.,

$\sigma_{1}^{* M}$ is close to one), the ethical type and the opportunistic type take the same action with almost a probability of one. Hence, distinguishing these two types is not easy for the voter, meaning that the incumbent's action in period 1 is not so informative about the value of $\alpha$. That is, political distrust does not substantially increase even after corruption, and thus the voter can punish the corrupt politician. This mechanism will be the key to the following analysis.

Klašnja and Tucker (2013) analyze whether voters punish a corrupt politician based on survey experiments. They then reveal that the voters' response is different across countries: in a low corruption country (Sweden), voters react negatively to corruption regardless of the state of the economy, whereas this is not the case in a high corruption country (Moldova). This fact suggests that whether voters think that corruption is widespread affects voters' voting strategy, which is consistent with our result.

\subsection{Equilibrium after the Good Outcome}

So far, we have seen that in the presence of model uncertainty, the bad outcome in period 1 undermines the politicians' collective reputation as well as the incumbent's individual reputation, resulting in a low electoral accountability in period 2. On the contrary, when the good outcome was observed in period 1, electoral accountability in period 2 becomes higher.

Proposition 4. (i) $\sigma_{2}^{* N}(0 \mid I)=\sigma_{2}^{* M}(0 \mid I)$.

(ii) $\sigma_{2}^{* N}(0 \mid C) \leq \sigma_{2}^{* M}(0 \mid C)$, where equality holds if and only if $r \leq 1$. 
When the incumbent is reelected, the politician's performance in period 2 is the same independently of the existence of model uncertainty because only the individual reputation of the incumbent politician matters. This is the same as in the case of corruption. The difference is in the case when the challenger is elected, which is noted in (ii). After observing the good outcome in period 1, the voter upwardly updates the probability of $\alpha$ being $\bar{\alpha}$ i.e., political trust increases. As a result, the challenger's performance becomes higher in the presence of model uncertainty.

Hence, model uncertainty makes the politician's performance more volatile depending on the politician's performance in period 1 . When period 1 performance is bad, the negative effect arises, while the positive effect arises when the performance is good. The next question is how this affects electoral accountability in period 1.

\section{Equilibrium in Period 1}

We next turn to the analysis of the equilibrium in period 1.

\subsection{Low Accountability}

In period 1, the opportunistic type faces a trade-off between implementing their own ideal policy and reelection. To be specific, the benefit of implementing policy 0 is given by $P^{*}(0)-P^{*}(1)$, which represents the extent of an increase in the reelection probability by choosing policy 0 . Model uncertainty affects this benefit of implementing policy 0 as follows:

Lemma 2. $P^{* M}(0) \leq P^{* N}(0)$, where equality holds only when $\sigma_{1}^{*}=1$. By combining Proposition 2. we have $P^{* M}(0)-P^{* M}(1) \leq P^{* N}(0)-P^{* N}(1)$, where equality holds only when $\sigma_{1}^{*}=1$.

As seen in Proposition 2, model uncertainty increases $P^{*}(1)$ i.e., it decreases the punishment for corruption. Furthermore, model uncertainty also decreases $P^{*}(0)$ i.e., it decreases the reward for non-corruption. When the incumbent politician in period 1 chooses non-corruption, the challenger's reputation also becomes larger because political trust increases. As a result, the incumbent's reelection probability does not become very large even after the good outcome. Consequently, the politician's benefit of non-corruption becomes smaller in the presence of model uncertainty.

This implies that the opportunistic type has a larger incentive to become corrupt in the presence of model uncertainty. We can show that there exists $\bar{\delta}$ such that $\sigma_{1}^{*}=1$ can be an equilibrium strategy if and only if $\delta \geq \bar{\delta}$. Similarly, there exists $\underline{\delta}$ such that $\sigma_{1}^{*}=0$ can be an equilibrium strategy if and only if $\delta \leq \underline{\delta}$. This is not surprising because smaller $\delta$ means that the benefit of implementing policy 0 is discounted more. Given these notations, we have the following result.

Proposition 5. Suppose that b is sufficiently large. Then, the following properties hold:

(i) $\bar{\delta}^{N}=\bar{\delta}^{M}$. 
(ii) If $\sigma_{1}^{* N}(\delta) \in(0,1), \sigma_{1}^{* M}(\delta)<\sigma_{1}^{* N}(\delta)$.

(iii) $\underline{\delta}^{N}<\underline{\delta}^{M}$

Hence, model uncertainty increases the equilibrium corruption level. In new democracies that have recently experienced democratization, voters would face a severe model uncertainty about politicians. This result indicates that such countries tend to experience severe corruption just because of model uncertainty.

Though we have compared the cases with and without model uncertainty, similar results hold for the degree of model uncertainty. To fix the idea, we focus on the effect on $\underline{\delta}$.

Fact 1. Suppose that $\phi=0.5, \bar{\alpha}=\alpha^{e}+\varepsilon$, and $\underline{\alpha}=\alpha^{e}-\varepsilon$, where $\varepsilon \in[0,0.5)$. Then, $\underline{\delta}^{M}$ is increasing in $\varepsilon$.

Under this parametric assumption, the larger $\varepsilon$ represents higher model uncertainty. When $\varepsilon=0$, the situation is reduced to the case without model uncertainty. This fact indicates that the higher model uncertainty makes the fully-unaccountable equilibrium more likely to exist. That is, there is a monotonic relationship between the degree of model uncertainty and the equilibrium corruption level.

\subsection{Multiplicity of Equilibria}

Without model uncertainty, the benefit of implementing the good policy $\left(P^{* N}\left(0 ; \sigma_{1}^{*}\right)-P^{* N}\left(1 ; \sigma_{1}^{*}\right)\right)$ is decreasing in $\sigma_{1}^{*}$. That is, as the probability of the opportunistic type choosing the good policy increases, the benefit of doing so decreases, implying strategic substitution. This relationship is obtained because when $\sigma_{1}^{*}$ is high, a lot of the opportunistic types choose the good policy and thus implementing the good policy does not serve as an informative signal of the incumbent being the good type. Consequently, we have a unique equilibrium. This property is pretty robust beyond our specific setting and many papers about political agency problems have found the same one (Besley, 2006).

Proposition 6. (i) $P^{* N}\left(0 ; \sigma_{1}^{*}\right)-P^{* N}\left(1 ; \sigma_{1}^{*}\right)$ is a decreasing function of $\sigma_{1}^{*}$.

(ii) The equilibrium is always unique in period 1.

However, in the presence of model uncertainty, this might not be the case, because there is a counter-acting effect. When policymaking in period 1 is uninformative about the incumbent's type as a result of high $\sigma_{1}^{*}$, policymaking in period 1 also becomes uninformative about the distribution i.e., the value of $\alpha$. That is, the higher $\sigma_{1}^{*}$ makes political trust less sensitive to policymaking in period 1 . Consequently, the larger $\sigma_{1}^{*}$ implies a smaller negative effect of model uncertainty on the benefit of implementing the good policy, which is created by the endogenous change in political trust. This can partly be seen in Proposition 3 . If this effect dominates the 


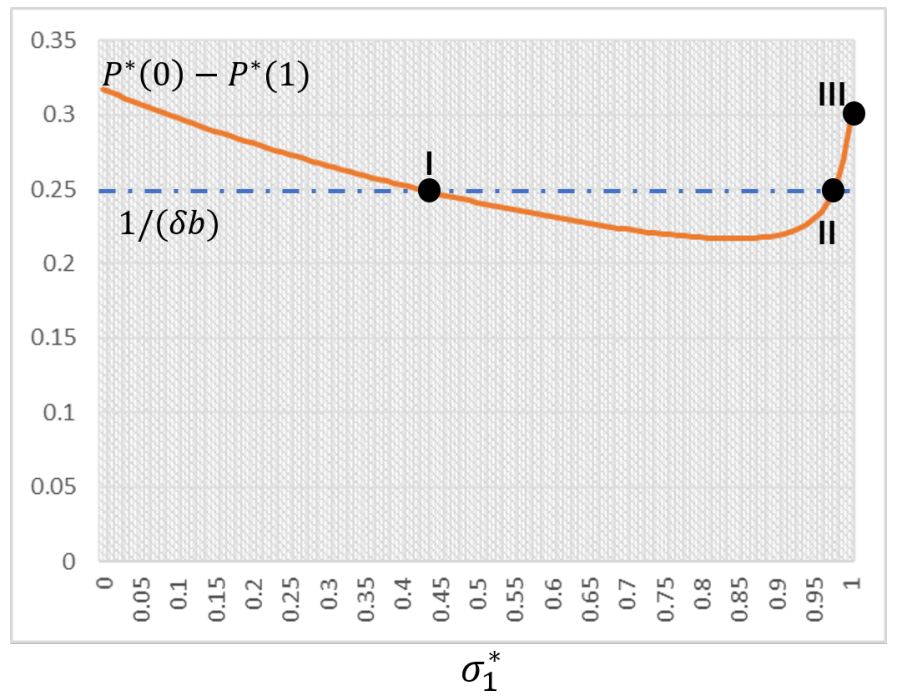

Figure 1: Multiple equilibria: $q=0.99 ; \bar{\alpha}=0.9 ; \underline{\alpha}=0.3 ; \phi=0.5 ; r=0 ; \delta b=4 ; \psi=0.5$.

strategic substitute effect, the game could exhibit strategic complementarity: the higher $\sigma_{1}^{*}$ leads to the larger benefit of implementing policy 0 . Indeed, we obtain the following property. Let $\alpha^{e^{\prime}} \equiv \phi \bar{\alpha}^{2}+(1-\phi) \underline{\alpha}^{2}$.

Proposition 7. (i) If and only if $q>\underline{q} \equiv \frac{\alpha^{e}\left(1-\alpha^{e}\right)}{\alpha^{e}+\alpha^{e^{\prime}}-2 \alpha^{e 2}} \in(0,1)$, there exists $\underline{\sigma}$ such that for $\sigma_{1}^{*} \in(\underline{\sigma}, 1], P^{* M}\left(0 ; \sigma_{1}^{*}\right)-P^{* M}\left(1 ; \sigma_{1}^{*}\right)$ is an increasing function of $\sigma_{1}^{*}$.

(ii) Suppose that $q>\underline{q}$. For some b and $\delta$, there exist multiple equilibria in period 1.

(i) argues that when $q$ is sufficiently large, the game exhibits locally strategic complementarity around $\sigma_{1}^{*}=1$. As a result, for certain parameter values, we have multiple equilibria. This can be seen in Figure 2. In the figure, we plot $P^{* M}(0)-P^{* M}(1)$ as the blue line. When $\sigma_{1}^{*}$ is sufficiently close to one, this value is increasing in $\sigma_{1}^{*}$ i.e., the game exhibits locally strategic complementarity. As an immediate consequence of this complementarity, multiple equilibria coexist.

To see this, suppose that $r=0$ as in the canonical two-period election model (Besley, 2006). In this case, the opportunistic type has an incentive to implement policy 0 in period 1 if and only if

$$
\delta b P^{*}(0)-1 \geq \delta b P^{*}(1) \Leftrightarrow P^{*}(0)-P^{*}(1) \geq \frac{1}{\delta b} .
$$

The orange solid line in Figure 2 is the left-hand side, whereas the blue dotted line is the right-hand side. Hence, in Figure 2 wherein $r=0$, we have three equilibria: two mixed strategy equilibria (I and II) 19 and one pure strategy equilibrium (III). In particular, in spite of the existence of the fully-accountable equilibrium, other equilibria in which the voter cannot

\footnotetext{
${ }^{19}$ The mixed strategy equilibrium II is not stable because of strategic complementarity (Echenique and Edlin.
} 2004). 
fully control the opportunistic type also coexist. This multiplicity of equilibria is never obtained without model uncertainty as seen in Proposition 6.

The role of model uncertainty can also be confirmed in the condition about $q$.

Fact 2. Suppose that $\phi=0.5, \bar{\alpha}=\alpha^{e}+\varepsilon$, and $\underline{\alpha}=\alpha^{e}-\varepsilon$, where $\varepsilon \in[0,0.5)$. Then, $\underline{q}$ is decreasing in $\varepsilon$. In particular, $\underline{q}=1$ when $\varepsilon=0$.

Proof . This is straightforward, and thus we omit the proof.

As $\varepsilon$ becomes smaller, the fluctuation of the political trust level becomes lower. The above fact indicates that a lower fluctuation of political trust (i.e., a lower degree of model uncertainty) makes strategic complementarity less likely to arise. Note that an arbitrary small level of model uncertainty could be enough for local strategic complementarity, because the above result indicates that for any $\varepsilon>0$, there exists $q$ such that the complementarity exists locally. In this sense, the case without model uncertainty - the situation the canonical model assumes - is a knife-edge case.

In summary, under model uncertainty, there are multiple equilibria, and which equilibrium is realized solely depends on the voter's expectation about the opportunistic type's performance $\sigma_{1}^{*}$. On the one hand, when the voter believes that $\sigma_{1}^{*}$ is high, both the punishment and the reward work so that the opportunistic type indeed chooses policy 0 with a high probability. On the other hand, when the voter believes that $\sigma_{1}^{*}$ is low, both the punishment and the reward do not work so that the opportunistic type chooses corruption with a high probability. As such, the voter's expectation is realized.

\section{Extension: Outsider Candidate}

So far, we have assumed that every candidate is drawn from the same distribution. Although this is reasonable when the candidates have similar backgrounds as political elites, in some cases, outsider candidates whose backgrounds are totally different from political elites are running for an election. To take this into account, we extend the model to allow the existence of outsider candidates.

We suppose that there are two types of politicians: elites and outsiders. Elites' preferences are the same as those given in the basic model, and the value of $\alpha$ is uncertain. On the contrary, outsiders have a different preference. They have no conflicts of interest with the voter so that they implement policy 0 for sure. Instead, they have only a low ability for policy implementation due to the lack of their expertise. As a result, when the outsider candidate is elected, the voter receives utility $-l$, where $l \in(0,1)$ and this is a deterministic variable ${ }^{20}$ In period 1 , the incumbent politician is assumed to be an elite politician. At the beginning of

\footnotetext{
${ }^{20}$ Such a trade-off is also assumed by Buisseret and Van Weelden (forthcoming) and Kishishita (2017), who analyze outsider candidates.
} 
period 2, three candidates are running for office: the incumbent elite politician, a new elite politician, and a new outsider politician. In the election, the voter reelects the incumbent politician if and only if $V(I)+\varepsilon \geq \max \{V(C),-l\}$. The outsider candidate wins the election when $-l>\max \{V(I)+\varepsilon, V(C)\}$. Otherwise, the new elite politician wins.

Here, in order to focus on meaningful cases, we suppose that the outsider candidate is never elected when the political trust level is maintained at the end of period 1; while the outsider candidate can be elected when the political trust level is severely undermined. Let $V(C)$ when the expected value of $\alpha$ at the beginning of period 2 is $\tilde{\alpha}$ be $V(C \mid \tilde{\alpha})$.

Assumption 3. $V(C \mid \underline{\alpha})<-l<V\left(C \mid \alpha^{e}\right)$ holds.

Under this assumption, the outsider candidate could win the election if and only if corruption arises and political distrust is magnified. That is, the following property is obtained.

Proposition 8. Suppose that there exists model uncertainty. $V(C)>-l$ always holds when $x_{1}=0$. On the contrary, there exists $\underline{\sigma} \in(0,1)$ such that $V(C) \leq-l$ if and only if $\sigma_{1}^{*} \leq \underline{\sigma}$ and $x_{1}=1$.

Proof . The first part comes from Assumption 3 because $V(C \mid \tilde{\alpha})$ is increasing in $\tilde{\alpha}$. The second part is also straightforward because $V(C)$ is increasing in $\sigma_{1}^{*}$ when $x_{1}=1$ from the previous discussion.

When corruption is observed, political distrust is magnified and the voter thinks that another elite politician is likely to be bad. Consequently, as a clean alternative, the voter supports the outsider candidate. This weakens our mechanism behind the effect of model uncertainty since the voter can punish the incumbent even if the voter distrusts elite candidates as a whole. Nonetheless, qualitatively, the same results hold.

\section{Proposition 9. Propositions 5 and 7 hold.}

Proof . Proposition 5. When $x_{1}=0, V(C)>-l$ so that $P_{M}^{*}(0)$ and $P_{N}^{*}(0)$ are the same as those in the absence of outsider candidates. Hence, $P_{M}^{*}(0) \leq P_{N}^{*}(0)$, which implies Proposition 5 .

Proposition 7. When $\sigma_{1}^{*}$ is close to one, $V(C)>-l$ so that $P_{M}^{*}(1)$ and $P_{N}^{*}(1)$ are also the same as those in the absence of outsider candidates. Hence, (i) of Proposition 7 holds.

That is, model uncertainty lowers electoral accountability and generates the self-fulfilling multiplicity of equilibria even in the presence of outsider candidates. This has the following novel implications about the rise of outsider candidates. First, model uncertainty induces the rise of outsider candidates because low accountability in period 1 encourages the rise of outsider candidates from Proposition 8 . Second, combining the multiplicity of equilibria with Proposition 8 implies that whether an outsider candidate arises at the center of politics depends on the voter's expectation about $\sigma_{1}^{*}$. That is, depending on the voter's expectation, the rise of the outsider candidate can be self-fulfilling. This indicates that without any change in the fundamentals, the 
rise of outsider candidates can suddenly emerge ${ }^{21}$ As such, model uncertainty significantly affects the rise of outsider candidates.

\section{Concluding Remarks}

It has been argued that political trust is a major determinant of the performance of a representative democracy. In order to evaluate the effect of political trust rigorously, we need to consider the nature of political trust that endogenously changes over time.

To explore this issue, we constructed a two-period political agency model wherein voters face uncertainty about the distribution of politicians' types (model uncertainty) as well as each individual politician's type. Such model uncertainty allows the endogenous change in political trust, whereas political trust is invariant without model uncertainty. We showed that model uncertainty undermines the performance of a representative democracy. Furthermore, it generates the multiplicity of equilibria: a high-accountability equilibrium and a low-accountability equilibrium coexist. We also discussed the rise of the outsider candidate. In new democracies, model uncertainty would be severe. Our results indicate that democratic performance tends to be low, and even similar countries could experience different performances depending on citizens' expectations in new democracies.

Before concluding this study, we discuss the remaining challenges for future research. First, extending the model to an infinite-horizon one might allow us to analyze the dynamics of political trust more profoundly. Second, in the presence of model uncertainty, people's ways of updating their beliefs might not be Bayesian (Ortoleva, 2012). Exploring this anomaly might be promising. These issues are left to future work.

\section{A. Omitted Proofs}

\section{A.1. Proof of Lemma 1}

The opportunistic type's payoff when choosing $x_{2}=0$ is given by

$$
-1+r \frac{\tilde{q}_{e}}{\tilde{q}_{e}+\sigma_{2}^{*} \tilde{q}_{o}},
$$

whereas the payoff when choosing $x_{2}=1$ is zero. Hence, the opportunistic type has an incentive to choose policy 2 if and only if (1) $\geq 0$.

First, consider the pure strategy $\sigma_{2}^{*}=1$. This constitutes an equilibrium if and only if (1) $\geq 0$, which can be rewritten as $r \geq \frac{\tilde{q}_{o}}{\tilde{q}_{e}}+1$.

\footnotetext{
${ }^{21}$ Mizuno and Okazawa (2018) find a self-fulfilling property of the rise of outsider candidates by emphasizing another mechanism: the role of voting as a signal of the voters' type, which is the private information of the voters.
} 
Second, consider another pure strategy $\sigma_{2}^{*}=0$. This constitutes an equilibrium if and only if (1) $\leq 0$, which can be rewritten as $r \leq 1$.

Lastly, consider the mixed strategy $\sigma_{2}^{*} \in(0,1)$. In this case, $(1)=0$ must hold, which can be rewritten as

$$
\sigma_{2}^{*}=\frac{(r-1) \tilde{q}_{e}}{\tilde{q}_{o}} .
$$

Because $\sigma_{2}^{*} \in(0,1), 1<r<\frac{\tilde{q}_{o}}{\tilde{q}_{e}}+1$ must hold.

\section{A.2. Proof of Proposition 1}

(i). Regardless of whether model uncertainty exists or not, if the voter observes $x_{1}=1$, the voter believes that there is no ethical type in period 2 when the incumbent is reelected. Hence, $\tilde{q}_{e}=0$. This directly implies (i) from Lemma 1 (i).

(ii). Suppose that the voter observes $x_{1}=1$. When the challenger is elected, the opportunistic type's equilibrium strategy in period 2 in the absence of model uncertainty is:

$$
\sigma_{2}^{* N}(1 \mid C)=\max \left\{0, \frac{(r-1) \alpha^{e}}{1-\alpha^{e}}\right\} .
$$

Note that $\sigma_{2}^{* N}<1$ from Assumption 2.

In addition, when the challenger is elected, the opportunistic type's equilibrium strategy in period 2 under model uncertainty is:

$$
\sigma_{2}^{* M}(1 \mid C)=\max \left\{0, \frac{(r-1) \tilde{\alpha}(1)}{1-\tilde{\alpha}(1)}\right\}
$$

where

$$
\begin{aligned}
\tilde{\alpha}(1) & =\phi(1) \bar{\alpha}+(1-\phi(1)) \underline{\alpha} \\
& =\frac{\phi\left[\left(1-\sigma_{1}^{*}\right)(1-\bar{\alpha}) q+1-q\right] \bar{\alpha}+(1-\phi)\left[\left(1-\sigma_{1}^{*}\right)(1-\underline{\alpha}) q+1-q\right] \underline{\alpha}}{\phi\left[\left(1-\sigma_{1}^{*}\right)(1-\bar{\alpha}) q+1-q\right]+(1-\phi)\left[\left(1-\sigma_{1}^{*}\right)(1-\underline{\alpha}) q+1-q\right]} \\
& =\frac{\alpha^{e}\left(1-q \sigma_{1}^{*}\right)-q\left(1-\sigma_{1}^{*}\right)\left(\phi \bar{\alpha}^{2}+(1-\phi) \underline{\alpha}^{2}\right)}{\left(1-\sigma_{1}^{*}\right)\left(1-\alpha^{e}\right) q+1-q} .
\end{aligned}
$$

Note that $\sigma_{2}^{* N}$ and $\sigma_{2}^{* M}$ are equal to zero if and only if $r \leq 1$. Hence,

$$
\sigma_{2}^{* N}(1 \mid C)-\sigma_{2}^{* M}(1 \mid C)=\max \left\{0,(r-1) \frac{\alpha^{e}-\tilde{\alpha}(1)}{\left(1-\alpha^{e}\right)(1-\tilde{\alpha})(1)}\right\} .
$$


Thus, it suffices to consider the difference between $\alpha^{e}$ and $\tilde{\alpha}(1)$ :

$$
\alpha^{e}-\tilde{\alpha}(1)=\frac{q\left(1-\sigma_{1}^{*}\right)\left(\phi \bar{\alpha}^{2}+(1-\phi) \underline{\alpha}^{2}-\alpha^{e 2}\right)}{\left(1-\sigma_{1}^{*}\right)\left(1-\alpha^{e}\right) q+1-q} .
$$

To this end, we show the following lemma.

\section{Lemma A.1.}

$$
\phi \bar{\alpha}^{2}+(1-\phi) \underline{\alpha}^{2}-\alpha^{e 2}>0
$$

Proof .

$$
\phi \bar{\alpha}^{2}+(1-\phi) \underline{\alpha}^{2}-\alpha^{e 2}=\phi(1-\phi)(\bar{\alpha}-\underline{\alpha})^{2}>0 .
$$

For the ease of notations, from now on, let $\alpha^{e^{\prime}} \equiv \phi \bar{\alpha}^{2}+(1-\phi) \underline{\alpha}^{2}$.

From Lemma A.1, $\alpha^{e}-\tilde{\alpha}(1)>0$. Hence, we have Proposition 1 (ii).

\section{A.3. Proof of Proposition 2}

As discussed in Proposition 11, politicians' strategies in period 2 are the same for all $r \in[0,1]$. Hence, without loss of generality, we consider only the case where $r \geq 1$.

From Proposition 1, when the voter observes $x_{1}=1$,

$$
V(I)-V(C)=-1-\left[-\left(1-\sigma_{2}^{*}\right) \tilde{\alpha} q-(1-q)\right],
$$

where $\tilde{\alpha}=\alpha^{e}$ without model uncertainty and $\tilde{\alpha}(1)$ with model uncertainty. In addition, the incumbent's reelection probability is

$$
\operatorname{Pr}(\varepsilon \geq V(C)-V(I))=\frac{1}{2}-\psi[V(C)-V(I)] .
$$

Hence, from Proposition 1, the incumbent's reelection probability under model uncertainty $P^{* M}(1)$ is

$$
P^{* M}(1)=\frac{1}{2}-\psi r q \frac{\alpha^{e}\left(1-q \sigma_{1}^{*}\right)-q\left(1-\sigma_{1}^{*}\right) \alpha^{e \prime}}{\left(1-\sigma_{1}^{*}\right)\left(1-\alpha^{e}\right) q+1-q} .
$$

Similarly, the incumbent's reelection probability in the absence of model uncertainty $P^{* N}(1)$ is

$$
P^{* N}(1)=\frac{1}{2}-\psi r \alpha^{e} q
$$

(5) and (6) yields the difference between $P^{* M}(1)$ and $P^{* N}(1)$ as

$$
P^{* M}(1)-P^{* N}(1)=\frac{\psi r q}{\left(1-\sigma_{1}^{*}\right)\left(1-\alpha^{e}\right) q+1-q} q\left(1-\sigma_{1}^{*}\right)\left(\alpha^{e \prime}-\alpha^{e 2}\right) .
$$


The above equation is non-negative from Lemma A.1. In addition, if and only if $\sigma_{1}^{*}=1$, the above equation is equal to zero.

\section{A.4. Proof of Proposition 3}

Differentiating (5) with respect to $\sigma_{1}^{*}$ yields

$$
\frac{\partial P^{* M}(1)}{\partial \sigma_{1}^{*}}=\frac{-\psi r q}{\left[\left(1-\sigma_{1}^{*}\right)\left(1-\alpha^{e}\right) q+1-q\right]^{2}} q(1-q)\left(\alpha^{e \prime}-\alpha^{e 2}\right) .
$$

From Lemma A.1, this is negative.

\section{A.5. Proof of Proposition 4}

(i). If the voter observes $x_{1}=0$ and the incumbent is reelected, $\tilde{q}_{e}$ is the same regardless of whether model uncertainty exists or not. Hence, from Lemma 1, (i) holds.

Specifically, the opportunistic type's equilibrium strategy in period 2 is

$$
\sigma_{2}^{* M}(0 \mid I)=\sigma_{2}^{* N}(0 \mid I)=\min \left\{\max \left\{\frac{(r-1) \tilde{q}_{e}}{\tilde{q}_{o}}, 0\right\}, 1\right\} .
$$

(ii). Suppose that the voter observes $x_{1}=0$. When the challenger is elected, the opportunistic type's strategy in period 2 in the absence of model uncertainty is

$$
\sigma_{2}^{* N}(0 \mid C)=\min \left\{\frac{(r-1) \alpha^{e}}{1-\alpha^{e}}, 0\right\}
$$

On the contrary, when the challenger is elected, the opportunistic type's equilibrium strategy in period 2 under model uncertainty is

$$
\sigma_{2}^{* M}(0 \mid C)=\min \left\{\frac{(r-1) \tilde{\alpha}(0)}{1-\tilde{\alpha}(0)}, 0\right\}
$$

Here,

$$
\tilde{\alpha}(0)=\phi(0) \bar{\alpha}+(1-\phi(0)) \underline{\alpha},
$$

where

$$
\phi(0)=\frac{\phi\left[\bar{\alpha} q+\sigma_{1}^{*}(1-\bar{\alpha}) q\right]}{\alpha^{2} q+\sigma_{1}^{*}\left(1-\alpha^{e}\right) q}
$$

That is,

$$
\tilde{\alpha}(0)=\frac{\alpha^{e^{\prime}}\left(1-\sigma_{1}^{*}\right)+\sigma_{1}^{*} \alpha^{e}}{\alpha^{e}+\left(1-\alpha^{e}\right) \sigma_{1}^{*}}
$$


Hence, the difference between $\sigma_{2}^{* M}(1 \mid C)$ and $\sigma_{2}^{* N}(0 \mid C)$ is given by

$$
\sigma_{2}^{* M}(0 \mid C)-\sigma_{2}^{* N}(0 \mid C)=\max \left\{0,(r-1) \frac{\left(1-\sigma_{1}^{*}\right)\left(\alpha^{e \prime}-\alpha^{e 2}\right)}{\left(1-\alpha^{e}\right)\left[\left(1-\sigma_{1}^{*}\right)\left(\alpha^{e}-\alpha^{e^{\prime}}\right)+\left(1-\alpha^{e}\right) \sigma_{1}^{*}\right]}\right\} .
$$

Here, $\alpha^{e}>\alpha^{e^{\prime}}>\alpha^{e 2}$. Hence, the second term is strictly larger than zero if and only if $r>1$. Therefore, (ii) is obtained.

\section{A.6. Proof of Lemma2}

As in the proof of Proposition 2, without loss of generality, we focus on the case where $r>1$. From Proposition 4, when the voter observes $x_{1}=0$, the incumbent's reelection probability under model uncertainty $P^{* M}(0)$ is given by

$$
P^{* M}(0)=\frac{1}{2}+\psi \min \left\{r \frac{\alpha^{e}\left(1-q \sigma_{1}^{*}\right)-q\left(1-\sigma_{1}^{*}\right) \alpha^{e \prime}}{\alpha^{e}+\left(1-\alpha^{e}\right) \sigma_{1}^{*}}, 1-r q \frac{\left(1-\sigma_{1}^{*}\right) \alpha^{e \prime}+\sigma_{1}^{*} \alpha^{e}}{\alpha^{e}+\left(1-\alpha^{e}\right) \sigma_{1}^{*}}\right\} .
$$

Similarly, the incumbent's reelection probability in the absence of model uncertainty $P^{* N}(0)$ is given by

$$
P^{* N}(0)=\frac{1}{2}+\min \left\{\psi r \alpha^{e} \frac{1-q\left(\alpha^{e}+\left(1-\alpha^{e}\right) \sigma_{1}^{*}\right)}{\alpha^{e}+\left(1-\alpha^{e}\right) \sigma_{1}^{*}}, \psi\left(1-r q \alpha^{e}\right)\right\}
$$

Hence, the difference between $P^{* M}(0)$ and $P^{* N}(0)$ is:

$$
P^{* M}(0)-P^{* N}(0)=\psi r q \min \left\{\frac{\left(1-\sigma_{1}^{*}\right)\left(\alpha^{e 2}-\alpha^{e \prime}\right)}{\alpha^{e}+\left(1-\alpha^{e}\right) \sigma_{1}^{*}}, \alpha^{e}-\frac{\left(1-\sigma_{1}^{*}\right) \alpha^{e \prime}+\sigma_{1}^{*} \alpha^{e}}{\alpha^{e}+\left(1-\alpha^{e}\right) \sigma_{1}^{*}}\right\} .
$$

This is non-positive from Lemma A.1 and equal to zero if and only if $\sigma_{1}^{*}=1$.

\section{A.7. Proof of Proposition 5}

Notice that the existence of equilibria is easy to follow from the continuity of the payoff function.

(i). Suppose $\sigma_{1}^{*}=1$. Then, $\sigma_{2}^{* M}(0 \mid I)=\sigma_{2}^{* N}(0 \mid I)<1$ from the Assumption 2 and Proposition 4. Hence, if and only if the following inequality holds, the opportunistic type has an incentive to choose $x_{1}=0$ :

$$
-1+\delta P(0) b \geq \delta P(1) b \Leftrightarrow \delta \geq b^{-1}(P(0)-P(1))^{-1}(\equiv \bar{\delta}) .
$$

From inequality $12, \bar{\delta}^{N}$ and $\bar{\delta}^{M}$ is

$$
\bar{\delta}^{N}=\bar{\delta}^{M}=b^{-1}\left(\psi r \alpha^{e}\right)^{-1} .
$$


(ii). Suppose that $\sigma_{1}^{* N}<1$. If and only if the following inequality holds, the opportunistic type has an incentive to choose $x_{1}=0$ :

$$
\begin{aligned}
& -1+\delta P(0)(b+\max \{r \pi(0,0)-1,0\}) \geq \delta P(1) b \\
& \Leftrightarrow \delta \geq[b(P(0)-P(1))+\max \{r \pi(0,0)-1,0\} P(0)]^{-1}(\equiv \underline{\delta})
\end{aligned}
$$

As later shown in Proposition 6(i), $\underline{\delta}$ is decreasing in $\sigma$ without model uncertainty. Furthermore, as later shown in Proposition 6(ii), the equilibrium in the absence of model uncertainty is unique. Hence, for all $\sigma_{1}>\sigma_{1}^{* N}, 13 p$ does not hold in the absence of model uncertainty. Then, from Lemma 2, (13) does not hold for all $\sigma_{1} \geq \sigma_{1}^{* N}$ in the presence of model uncertainty. This implies that $\sigma_{1}^{* M}<\sigma_{1}^{* N}$.

(iii). Suppose $\sigma_{1}^{*}=0$. Then, $\sigma_{2}^{* M}(0 \mid I)=\sigma_{2}^{* N}(0 \mid I)=1$. Hence, if and only if the following inequality holds, the opportunistic type has an incentive to choose $x_{1}=1,2$

$$
-1+\delta P(0)(b+r-1) \leq \delta P(1) b \Leftrightarrow \delta \leq[b(P(0)-P(1))+(r-1) P(0)]^{-1}(\equiv \underline{\delta}) .
$$

Hence, from Lemma $2, \underline{\delta}^{N}<\underline{\delta}^{M}$. Consequently, we obtain the proposition.

\section{A.8. Proof of Fact 1}

$\varepsilon$ only affects $\alpha^{e^{\prime}}$. Hence, it suffices to consider the effect of $\varepsilon$ through a change in $\alpha^{e \prime}$. First, observe that $P^{M}(0)$ is decreasing in $\alpha^{e^{\prime}}$, while $P^{M}(1)$ is increasing in $\alpha^{e^{\prime}}$. From $(14)$, this directly implies that $\underline{\delta}_{M}$ is increasing in $\alpha^{e^{\prime}}$. Furthermore, simple calculation yields $\alpha^{e^{\prime}}=\alpha^{e 2}+\varepsilon^{2}$, implying that $\alpha^{e \prime}$ is increasing in $\varepsilon$. Hence, $\underline{\delta}_{M}$ is increasing in $\varepsilon$.

\section{A.9. Proof of Proposition 6}

The second part is a direct consequence of the first part, and thus we prove only (i). For simplicity, we focus on the case where $\sigma_{1}^{*}>0$. From the previous discussion,

$$
P^{* N}\left(0 ; \sigma_{1}^{*}\right)-P^{* N}\left(1 ; \sigma_{1}^{*}\right)=\frac{\psi r \alpha^{e}}{\alpha^{e}+\left(1-\alpha^{e}\right) \sigma_{1}^{*}}
$$

which is obviously decreasing in $\sigma_{1}^{*}$.

\section{A.10. Proof of Proposition 7}

The second part is a direct consequence of the first part, and thus we prove only (i). Without loss of generality, we again focus on the case where $r \geq 1$.

${ }^{22} \pi(0,0)=1$. 
Suppose that $\sigma_{1}^{*}$ is close to one. Then, $\sigma_{2}^{* M}(0 \mid I)<1$ so that

$$
P^{* M}(0)=\frac{1}{2}+\psi r \frac{\alpha^{e}\left(1-q \sigma_{1}^{*}\right)-q\left(1-\sigma_{1}^{*}\right) \alpha^{e^{\prime}}}{\alpha^{e}+\left(1-\alpha^{e}\right) \sigma_{1}^{*}} .
$$

Hence, differentiating $P^{* M}(0)-P^{* M}(1)$ with respect to $\sigma_{1}^{*}$ yields

$$
\begin{aligned}
& \frac{\partial\left(P^{* M}(0)-P^{* M}(1)\right)}{\partial \sigma_{1}^{*}} \\
& =\psi r q\left(\alpha^{e^{\prime}}-\alpha^{e}\right)\left[\frac{1}{\alpha^{e}+\left(1-\alpha^{e}\right) \sigma_{1}^{*}}+\frac{q}{\left(1-\sigma_{1}^{*}\right)\left(1-\alpha^{e}\right) q+1-q}\right] \\
& +\psi r\left(1-\alpha^{e}\right)\left[\alpha^{e}\left(1-q \sigma_{1}^{*}\right)-q\left(1-\sigma_{1}^{*}\right) \alpha^{e^{\prime}}\right]\left\{\frac{-1}{\left[\alpha^{e}+\left(1-\alpha^{e}\right) \sigma_{1}^{*}\right]^{2}}+\frac{q^{2}}{\left[\left(1-\sigma_{1}^{*}\right)\left(1-\alpha^{e}\right) q+1-q\right]^{2}}\right\} .
\end{aligned}
$$

It suffices to prove that $(16)$ is positive when $\sigma_{1}^{*}=1$. By substituting $\sigma_{1}^{*}=1$ into $(16)$, we obtain

$$
\begin{aligned}
\left.\frac{\partial\left(P^{* M}(0)-P^{* M}(1)\right)}{\partial \sigma_{1}^{*}}\right|_{\sigma_{1}^{*}=1} & =\psi r\left\{q\left(\alpha^{e \prime}-\alpha^{e}\right)\left(1+\frac{q}{1-q}\right)+\left(1-\alpha^{e}\right) \alpha^{e}(1-q)\left[-1+\frac{q^{2}}{(1-q)^{2}}\right]\right\} \\
& =\psi r\left[q\left(\alpha^{e \prime}-\alpha^{e}\right) \frac{1}{1-q}+\left(1-\alpha^{e}\right) \alpha^{e} \frac{-1+2 q}{1-q}\right] \\
& =\frac{\psi r}{1-q}\left[q\left(\alpha^{e \prime}-\alpha^{e}\right)+\left(1-\alpha^{e}\right) \alpha^{e}(2 q-1)\right] \\
& =\frac{\psi r}{1-q}\left[q\left(\alpha^{e}+\alpha^{e^{\prime}}-2 \alpha^{e 2}\right)-\alpha^{e}\left(1-\alpha^{e}\right)\right]
\end{aligned}
$$

This is positive if and only if

$$
q\left(\alpha^{e}+\alpha^{e^{\prime}}-2 \alpha^{e 2}\right)-\alpha^{e}\left(1-\alpha^{e}\right)>0 \Leftrightarrow q>\underline{q}=\frac{\alpha^{e}\left(1-\alpha^{e}\right)}{\alpha^{e}+\alpha^{e^{\prime}}-2 \alpha^{e^{2}}} .
$$

Hence, if and only if $q$ satisfies this inequality, there exists $\underline{\sigma}$ such that for $\sigma_{1}^{*} \in(\underline{\sigma}, 1]$, $P^{* M}\left(0 ; \sigma_{1}^{*}\right)-P^{* M}\left(1 ; \sigma_{1}^{*}\right)$ is an increasing function of $\sigma_{1}^{*}$.

Notice that $\underline{q} \in(0,1)$ because $\alpha^{e}-\alpha^{e 2}>\alpha^{e^{\prime}}-\alpha^{e 2}>0$ and

$$
\underline{q}=\frac{\alpha^{e}-\alpha^{e 2}}{\alpha^{e}-\alpha^{e 2}+\alpha^{e^{\prime}}-\alpha^{e 2}}
$$

\section{References}

Agerberg, Mattias. 2019. "The Lesser Evil? Corruption Voting and the Importance of Clean Alternatives." Comparative Political Studies, forthcoming. 
Andvig, Jens Chr, and Karl Ove Moene. 1990. "How Corruption May Corrupt." Journal of Economic Behavior \& Organization, 13(1): 63-76.

Ashworth, Scott, Ethan Bueno de Mesquita, and Amanda Friedenberg. 2017. "Accountability and Information in Elections." American Economic Journal: Microeconomics, 9(2): 95138.

Avis, Eric, Claudio Ferraz, and Frederico Finan. 2018. "Do Government Audits Reduce Corruption? Estimating the Impacts of Exposing Corrupt Politicians." Journal of Political Economy, 126(5): 1912-1964.

Bade, Sophie. 2013. "Ambiguity Aversion in Models of Political Economy." Journal of Institutional and Theoretical Economics, 169(1): 90-106.

Banks, Jeffrey S, and Rangarajan K Sundaram. 1990. "Incumbents, Challengers, and Bandits: Bayesian Learning in a Dynamic Choice Model." University of Rochester-Center for Economic Research (RCER).

Besley, Timothy. 2006. Principled Agents?: The Political Economy of Good Government. Oxford University Press.

Besley, Timothy, and Anne Case. 1995. "Incumbent Behavior: Vote-seeking, Tax-setting, and Yardstick Competition.” The American Economic Review, 85(1): 25.

Besley, Timothy, and Michael Smart. 2007. "Fiscal Restraints and Voter Welfare." Journal of Public Economics, 91(3-4): 755-773.

Boas, Taylor C, F Daniel Hidalgo, and Marcus André Melo. 2019. "Norms versus Action: Why Voters Fail to Sanction Malfeasance in Brazil." American Journal of Political Science, 63(2): 385-400.

Buisseret, Peter, and Richard Van Weelden. forthcoming. "Crashing the Party? Elites, Outsiders, and Elections." American Journal of Political Science.

Burdett, Kenneth, and Tara Vishwanath. 1988. "Declining Reservation Wages and Learning." The Review of Economic Studies, 55(4): 655-665.

Chen, Heng, and Wing Suen. 2016. "Falling Dominoes: A Theory of Rare Events and Crisis Contagion." American Economic Journal: Microeconomics, 8(1): 228-55.

Chen, Heng, and Wing Suen. 2017. "Aspiring for Change: A Theory of Middle Class Activism." The Economic Journal, 127(603): 1318-1347.

Chong, Alberto, Ana L De La O, Dean Karlan, and Leonard Wantchekon. 2014. "Does Corruption Information Inspire the Fight or Quash the Hope? A Field Experiment in Mexico on Voter Turnout, Choice, and Party Identification." The Journal of Politics, 77(1): 55-71.

Crozier, Michel, Samuel P Huntington, and Joji Watanuki. 1975. The Crisis of Democracy. New York University Press New York.

Dewan, Torun, and Rafael Hortala-Vallve. 2019. "Electoral competition, control and learning." British Journal of Political Science, 49(3): 923-939. 
Duggan, John, and César Martinelli. 2017. "The Political Economy of Dynamic Elections: Accountability, Commitment, and Responsiveness." Journal of Economic Literature, 55(3): 916-84.

Echenique, Federico, and Aaron Edlin. 2004. "Mixed Equilibria are Unstable in Games of Strategic Complements." Journal of Economic Theory, 1(118): 61-79.

Fong, Christian, Neil Malhotra, and Yotam Margalit. 2019. "Political Legacies: Understanding Their Significance to Contemporary Political Debates." PS: Political Science \& Politics, 52(3): 451-456.

Gilboa, Itzhak, and David Schmeidler. 1989. "Maxmin Expected Utility with Non-unique Prior." Journal of Mathematical Economics, 18(2): 141-153.

Glaeser, Edward L, and Raven E Saks. 2006. "Corruption in America." Journal of Public Economics, 90(6-7): 1053-1072.

Guiso, Luigi, Helios Herrera, Massimo Morelli, and Tommaso Sonno. 2017. "Demand and Supply of Populism."

Holmström, Bengt. 1999. "Managerial Incentive Problems: A Dynamic Perspective." The Review of Economic Studies, 66(1): 169-182.

Kartik, Navin, and Richard Van Weelden. 2019a. "Informative Cheap Talk in Elections." The Review of Economic Studies, 86(2): 755-784.

Kartik, Navin, and Richard Van Weelden. 2019b. "Reputation Effects and Incumbency (Dis) Advantage.” Quarterly Journal of Political Science, 14(2): 131-157.

Kishishita, Daiki. 2017. “(Not) Delegating Decisions to Experts: The Effect of Uncertainty on Populism." mimeo.

Klašnja, Marko, and Joshua A Tucker. 2013. "The Economy, Corruption, and the Vote: Evidence from Experiments in Sweden and Moldova." Electoral Studies, 32(3): 536-543.

Klašnja, Marko, Andrew T Little, and Joshua A Tucker. 2018. "Political Corruption Traps." Political Science Research and Methods, 6(3): 413-428.

Levin, Jonathan. 2009. “The Dynamics of Collective Reputation.” The BE Journal of Theoretical Economics, 9(1).

Mauro, Paolo. 2004. "The Persistence of Corruption and Slow Economic Growth.” IMF staff papers, 51(1): 1-18.

Meirowitz, Adam, and Joshua A Tucker. 2013. "People Power or a One-Shot Deal? A Dynamic Model of Protest." American Journal of Political Science, 57(2): 478-490.

Mishra, Ajit. 2006. "Persistence of Corruption: Some Theoretical Perspectives." World Development, 34(2): 349-358.

Mizuno, Nobuhiro, and Ryosuke Okazawa. 2018. "Why Do Voters Elect Less Qualified Candidates?" mimeo. 
Ortoleva, Pietro. 2012. "Modeling the Change of Paradigm: Non-Bayesian Reactions to Unexpected News." American Economic Review, 102(6): 2410-36.

Rock, Michael T. 2009. "Corruption and Democracy." The Journal of Development Studies, 45(1): $55-75$.

Seligson, Mitchell A. 2002. "The Impact of Corruption on Regime Legitimacy: A Comparative Study of Four Latin American Countries.” The Journal of Politics, 64(2): 408-433.

Svolik, Milan. 2008. "Authoritarian Reversals and Democratic Consolidation." American Political Science Review, 102(2): 153-168.

Svolik, Milan. 2013. "Learning to Love Democracy: Electoral Accountability and the Success of Democracy.” American Journal of Political Science, 57(3): 685-702.

Tirole, Jean. 1996. "A Theory of Collective Reputations (with Applications to the Persistence of Corruption and to Firm Quality)." The Review of Economic Studies, 63(1): 1-22.

Treisman, Daniel. 2000. "The Causes of Corruption: A Cross-National Study." Journal of Public Economics, 76(3): 399-457.

Van der Meer, Tom WG. 2017. "Political Trust and the "Crisis of Democracy"," In Oxford Research Encyclopedia of Politics. 